\title{
Advances in Understanding Activation and Function of the NLRC4 Inflammasome
}

\author{
Balamurugan Sundaram and Thirumala-Devi Kanneganti *
}

\section{check for}

updates

Citation: Sundaram, B.; Kanneganti, T.-D. Advances in Understanding Activation and Function of the NLRC4 Inflammasome. Int. J. Mol. Sci. 2021, 22, 1048. https://doi.org/ $10.3390 /$ ijms 22031048

Academic Editor: Thomas A. Kufer Received: 31 December 2020

Accepted: 16 January 2021

Published: 21 January 2021

Publisher's Note: MDPI stays neutral with regard to jurisdictional claims in published maps and institutional affiliations.

Copyright: (c) 2021 by the authors. Licensee MDPI, Basel, Switzerland. This article is an open access article distributed under the terms and conditions of the Creative Commons Attribution (CC BY) license (https:// creativecommons.org/licenses/by/ $4.0 /)$.
Department of Immunology, St. Jude Children's Research Hospital, Memphis, TN 38105, USA; balamurugan.sundaram@stjude.org

* Correspondence: Thirumala-devi.kanneganti@stjude.org; Tel.: +1-(901)-595-3634; Fax: +1-(901)-595-5766

\begin{abstract}
Innate immune receptors initiate a host immune response, or inflammatory response, upon detecting pathogen-associated molecular patterns (PAMPs) and damage-associated molecular patterns (DAMPs). Among the innate immune receptors, nucleotide-binding oligomerization domain (NOD)-like receptors (NLRs) play a pivotal role in detecting cytosolic PAMPs and DAMPs. Some NLRs can form a multiprotein cytosolic complex known as the inflammasome. Inflammasome activation triggers caspase-1-mediated cleavage of the pore-forming protein gasdermin D (GSDMD), which drives a form of inflammatory cell death called pyroptosis. Parallelly, activated caspase- 1 cleaves immature cytokines pro-IL-1 $\beta$ and pro-IL-18 into their active forms, which can be released via GSDMD membrane pores. The NLR family apoptosis inhibitory proteins (NAIP)-NLR family caspase-associated recruitment domain-containing protein 4 (NLRC4) inflammasome is important for mounting an immune response against Gram-negative bacteria. NLRC4 is activated through NAIPs sensing type 3 secretion system (T3SS) proteins from Gram-negative bacteria, such as Salmonella Typhimurium. Mutations in NAIPs and NLRC4 are linked to autoinflammatory disorders in humans. In this review, we highlight the role of the NAIP/NLRC4 inflammasome in host defense, autoinflammatory diseases, cancer, and cell death. We also discuss evidence pointing to a role of NLRC4 in PANoptosis, which was recently identified as a unique inflammatory programmed cell death pathway with important physiological relevance in a range of diseases. Improved understanding of the NLRC4 inflammasome and its potential roles in PANoptosis paves the way for identifying new therapeutic strategies to target disease.
\end{abstract}

Keywords: NOD-like receptors; NLR; NLRC4; NAIP; IRF8; inflammasome; cell death; pyroptosis; apoptosis; necroptosis; PANoptosis; PANoptosome; Gram-negative bacteria; Salmonella

\section{Introduction}

Innate immunity is the front-line defense mechanism to protect the host from various pathogenic and sterile insults. The innate immune system is triggered by pathogenassociated molecular patterns (PAMPs), which are components of infectious agents, and damage-associated molecular patterns (DAMPs), which are released during cellular or tissue damage. PAMPs and DAMPs are detected by germline-encoded host sensors called pattern recognition receptors (PRRs) [1,2], and this detection and subsequent response are critical for host survival. Based on their localization, PRRs are classified as membranebound PRRs and cytoplasmic PRRs. Membrane-bound PRRs include Toll-like receptors (TLRs) and C-type lectin receptors (CLRs), whereas cytoplasmic PRRs include nucleotidebinding oligomerization domain (NOD)-like receptors (NLRs), absent in melanoma 2 (AIM2)-like receptors (ALRs), and RIG-I-like receptors (RLRs). NLRs recognize a diverse array of ligands which can be from self or non-self, including pathogens. After sensing the ligands, some of the NLR family members assemble an inflammasome, which is a cytosolic multiprotein complex. Inflammasome assembly drives the activation of caspase-1, which processes IL-1 $\beta$ and IL-18 to produce their active forms and cleaves gasdermin D 
(GSDMD) to trigger a form of inflammatory cell death known as pyroptosis [3-5]. Due to their importance in inflammation and host response to pathogens, mutations in NLRs are associated with human autoimmune and autoinflammatory disorders. Although NLR family pyrin domain (PYD)-containing 3 (NLRP3) is the best-characterized inflammasome sensor, several other sensors, including NLRP1, NLR apoptosis inhibitory protein (NAIP)NLR family caspase recruitment domain (CARD)-containing protein 4 (NLRC4), NLRP6, NLRP9, absent in melanoma 2 (AIM2), and Pyrin, can also form inflammasomes and participate in regulating the host immune and inflammatory response [6-8].

NLRC4 plays a critical role in detecting Gram-negative bacteria in the cytoplasm, and it was initially discovered and called IPAF (ICE protease-activating factor) for its ability to activate caspase-1 [9]. NLRC4 features a three-domain structure: an amino-terminal CARD, a central nucleotide-binding domain (NACHT), and a carboxy-terminal leucine-rich repeat domain (LRR) (Figure 1).

\section{NLRC4 Inflammasome}

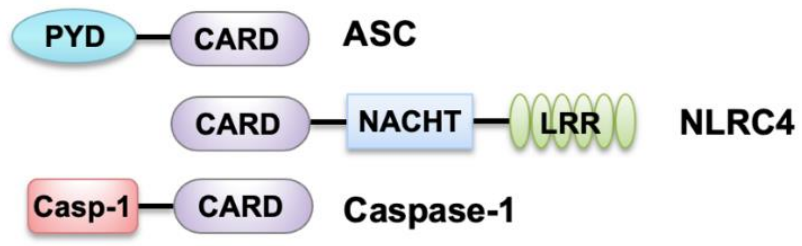

NAIP

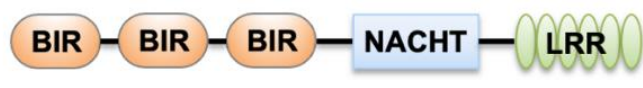

Figure 1. Domains of nucleotide-binding oligomerization domain (NOD)-like receptors (NLR) family caspase recruitment domain-containing protein 4 (NLRC4) inflammasome components and NLR family apoptosis inhibitory proteins (NAIPs). NLRC4 contains an N-terminal caspase recruitment domain (CARD), a central nucleotide-binding domain (NACHT), and a C-terminal leucine-rich repeat (LRR) domain. Both apoptosis-associated speck-like protein containing a CARD (ASC) and caspase-1 contain a CARD in addition to a pyrin (PYD) and caspase-1 (Casp-1) domain, respectively. Like NLRC4, NAIPs also contain a central NACHT and a C-terminal LRR domain, along with N-terminal baculovirus IAP-repeat (BIR) domains.

NLRC4 can associate with pro-caspase- 1 directly through CARD-CARD interactions, which triggers the processing and activation of caspase-1 [10]. Additionally, the adaptor molecule ASC (apoptosis-associated speck-like protein containing a CARD), encoded by the gene Pycard, can also facilitate this interaction. Activated NLRC4 can associate with ASC and colocalizes with the ASC-containing speck during Salmonella Typhimurium infection [11,12]. ASC contains a PYD and a CARD (Figure 1); its CARD is critical for optimal caspase- 1 recruitment into the speck to allow its activation and proteolytic cleavage of pro-IL-1 $\beta$ and pro-IL-18 [11-13]. Further, activated caspase-1 drives proteolytic cleavage of the pore-forming protein GSDMD, allowing the N-terminus of GSDMD to oligomerize in the host cell membrane which results in pore formation that causes pyroptosis and the release of cytokines and alarmins (Figure 2). NAIPs act as upstream sensors for NLRC4 inflammasome assembly. They contain an N-terminal baculovirus IAP-repeat (BIR) domain, a central NACHT, and a carboxy-terminal LRR [6] (Figure 1). NAIPs are crucial for detecting bacterial ligands in the cytoplasm, and their association with NLRC4 triggers NAIP-NLRC4 inflammasome activation [6] (Figure 2). 


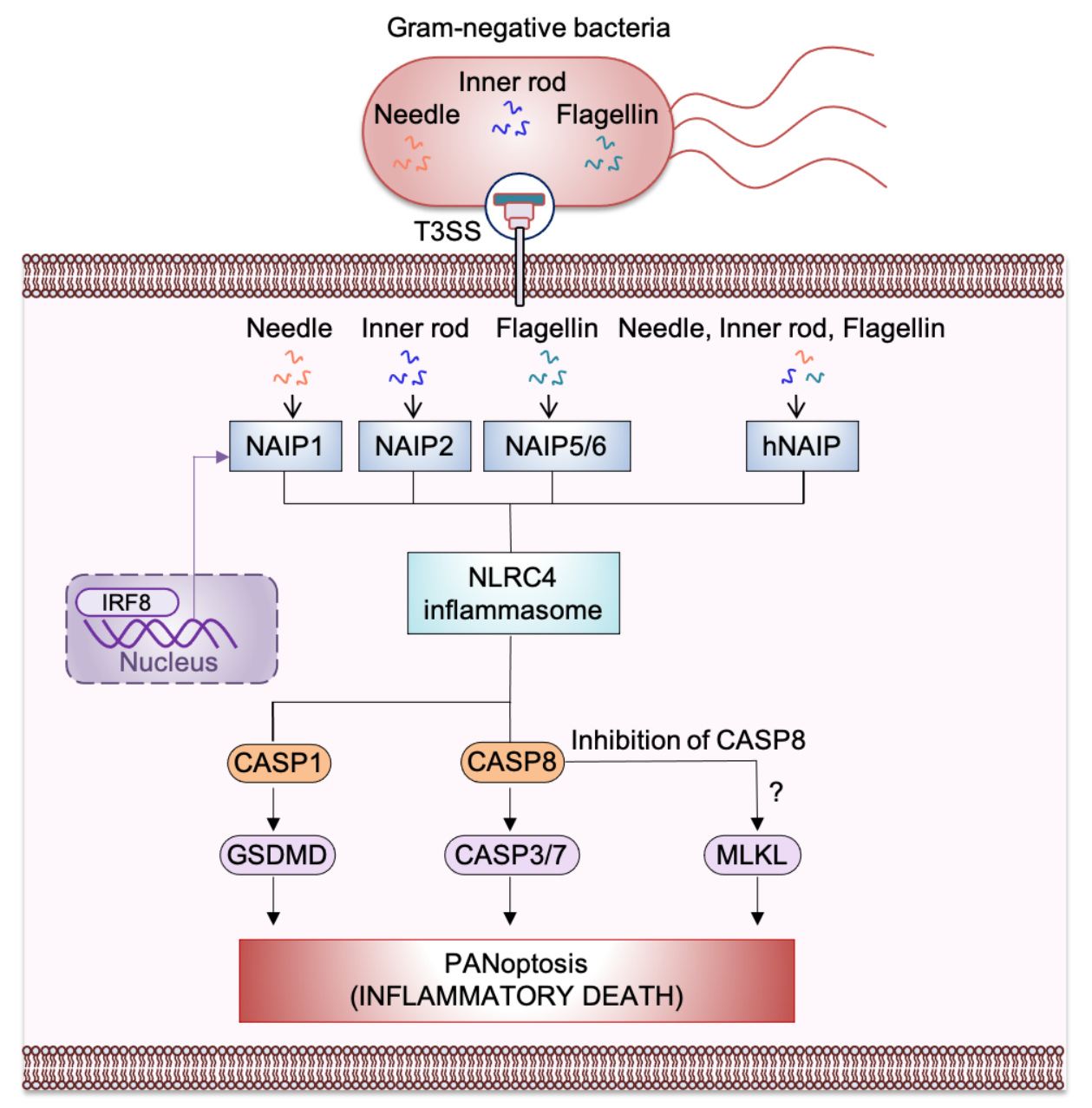

Figure 2. Mechanism of nucleotide-binding oligomerization domain (NOD)-like receptor (NLR) family apoptosis inhibitory protein (NAIP)-NLR family caspase recruitment domain-containing protein 4 (NLRC4) inflammasome-mediated PANoptosis, inflammatory cell death. Ligands from Gram-negative bacteria such as needle and inner rod protein of the Type 3 secretion system (T3SS) can be detected by murine NAIP1 and NAIP2, respectively, whereas flagellin can be detected by murine NAIP5/NAIP6. The single human NAIP (hNAIP) detects all the T3SS proteins such as needle, inner rod protein, and flagellin. After detecting T3SS proteins, NAIP associates with NLRC4 to induce activation of the NAIP/NLRC4 inflammasome. This activation results in inflammasome assembly and the cleavage and activation of caspase-1 (CASP1). Activated CASP1 triggers gasdermin D (GSDMD)-mediated pyroptosis. NLRC4 also activates caspase-8 (CASP8), which goes on to activate caspase-3/-7 (CASP3/7) to trigger apoptosis. Activation of the necroptotic pathway has also been observed during $S$. Typhimurium infection; this may occur through inhibition of CASP8. NAIPs are transcriptionally induced by interferon regulatory factor 8 (IRF8).

In this review, we will focus on the established functions of NLRC4 along with the most recent findings centered on the role of the NLRC4 inflammasome during infectious and autoinflammatory diseases. We will cover NAIP proteins and their role in ligand detection and NLRC4 inflammasome activation. Finally, we will discuss the role of NLRC4 in cell death and highlight emerging evidence pointing to its potential importance in PANoptosis, which would be interesting to investigate in future studies on inflammasome and cell death biology to identify new strategies to promote host defense while preventing excess inflammation. 


\section{Nucleotide-Binding Oligomerization Domain (NOD)-Like Receptor (NLR) Family Caspase-Associated Recruitment Domain-Containing Protein 4 (NLRC4)—An Innate Cytosolic Sensor}

In 2004, researchers first provided genetic proof that Nlrc4-deficient bone marrowderived macrophages (BMDMs) fail to activate caspase- 1 and pyroptosis after exposure to $S$. Typhimurium [14]. Later studies identified that $S$. Typhimurium flagellin and flagellin from the Gram-negative bacteria Legionella pneumonia can activate NLRC4, which subsequently triggers activation of caspase-1 [15-18]. Several pathogens are now known to possess flagellin-like virulence factors which can participate in the activation of the NLRC4 inflammasome; examples include $S$. Typhimurium (PrgJ), Burkholderia pseudomallei (BsaK), Escherichia coli (EprJ and Escl), Shigella flexneri (Mxil), and Pseudomonas aeruginosa (Pscl) [19]. Additionally, the NLRC4 inflammasome can be activated in certain cases without flagellin during bacteria exposure [16]. Overall, these findings demonstrate that NLRC4 is an important innate immune regulator that detects bacterial virulence factors.

NAIPs act as upstream immune sensor proteins for NLRC4 inflammasome activation. The murine genome encodes a total of seven NAIPs whereas the human genome encodes only one (hNAIP) [20]. In mice, NAIP5 and NAIP6 can activate NLRC4 specifically in response to bacterial flagellin [21]. NAIP5 directly interacts with flagellin and promotes the physical NAIP5-NLRC4 association which triggers NLRC4 inflammasome activation [21,22]. The related NAIP2 functions similarly to NAIP5 and serves as a specific inflammasome receptor for type III secretion system (T3SS) rod proteins such as S. Typhimurium PrgJ and B. pseudomallei BsaK [22]. hNAIP is functionally similar to murine NAIP1 in that they both sense the T3SS needle protein $[23,24]$. Furthermore, hNAIP can trigger NLRC4 inflammasome activation in response to both T3SS components and flagellin $[25,26]$. CprI, a Chromobacterium violaceum T3SS protein, is specifically recognized by hNAIP to trigger NLRC4 inflammasome activation [22].

The expression of NAIPs and NLRC4 are regulated by the interferon regulatory factor 8 (IRF8) transcription factor during bacterial infection [27] (Figure 2). IRF8 has been shown to be specifically required for activation of the NLRC4 inflammasome in BMDMs during S. Typhimurium, Burkholderia thailandensis, or P. aeruginosa infection. In vivo, Irf8-deficient mice are highly susceptible to bacterial infection compared with wildtype animals, confirming the critical role of IRF8 in NAIP/NLRC4 inflammasome activation [27]. Altogether, NAIPs act as an upstream sensor molecule that helps to recognize cytosolic PAMPs for NLRC4 inflammasome activation.

\section{Role of NLRC4 in Host Defense}

The innate immune function of the NLRC4 inflammasome has been extensively studied during bacterial infections, especially the foodborne bacterium $S$. Typhimurium. Studies have documented that Nlrc4-deficient animals are more susceptible to $S$. Typhimurium infection and have increased bacterial loads in the cecum, liver, and spleen compared with control animals [11,28-31], suggesting that NLRC4 is indispensable to protect the host from $S$. Typhimurium infection. However, similar studies have demonstrated that Nlrc4 knockout mice have no difference in bacterial load compared to wildtype mice after $S$. Typhimurium infection [13,31,32]. Functional redundancies between NLRC4 and NLRP3 could be the reason for these conflicting results. Indeed, later studies have shown that Nlrc4 and Nlrp3 double knockout mice are highly susceptible to $S$. Typhimurium and have increased bacterial loads in the spleen, liver, and mesenteric lymph nodes compared with control animals [13]. Other potential factors that could be contributing to the conflicting results observed in studies of NLRC4 during $S$. Typhimurium infection include differences in the bacterial strain used for infection, the route of bacterial administration, the genetic background of the mice used, and the gut microbiota of mice housed in different animal facilities. The intricate relationship between the gut microbiota and inflammasome activation has made it clear that using littermate controls is essential for obtaining reliable results from in vivo experiments $[33,34]$. Littermates are preferable to antibiotic depletion of the native microbiome, as treating mice with antibiotics can cause gut injury which was found to be 
associated with sepsis-like disease and the systemic spread of a multidrug-resistant $E$. coli pathobiont which can activate the NAIP5-NLRC4 inflammasome [35], further confounding results. Despite these conflicting findings, it is clear that NLRC4 is important in sensing bacterial ligands during $S$. Typhimurium infection [11,28-31].

Similar to $S$. Typhimurium, another enteric bacterial pathogen Citrobacter rodentium causes increased pathology and hyper-susceptibility in mice deficient in Nlrp3, Nlrc4, and Casp1, suggesting a critical role for NLRC4 in host defense against $C$. rodentium [36]. In addition to the role of NLRC4 in immune cells from the hematopoietic compartment during this infection, NLRC4 activation in the non-hematopoietic cellular compartment also occurs, especially in gut epithelial cells. Transplanting wildtype bone marrow cells to Nlrc4 ${ }^{-/-}$mice using a bone marrow chimera technique does not control the C. rodentium pathogen load, suggesting NLRC4 is important in the non-hematopoietic compartment [37]. Follow-up studies confirmed the essential functions of NLRC4 in the non-hematopoietic compartment by using tissue-specific gene knockout mice. Similar results have been observed with other pathogens. For example, mouse gut epithelial-specific deletion of Naip1-6 leads to an increased pathogen load after Salmonella infection [29]. Later studies showed that the expulsion of infected enterocytes relies on NLRC4 by using gut epitheliumspecific Nlrc4 knockout mice [30].

Apart from its importance in the host response to these enteric pathogens, NLRC4 also plays a crucial role in eliminating non-enteric bacteria. The NAIP-NLRC4 inflammasome can be activated by the flagellated pneumonia-causing bacteria Legionella pneumophila. Nlrc4-deficient mice fail to clear L. pneumophila upon nasal infection, while wildtype mice can clear the pathogen [38-41]. Similar to the importance of NLRC4 during infection with L. pneumophila, Nlrc4-deficient mice infected with other Legionella species, including L. micdadei, L. bozemanii, L. gratiana, and L. rubrilucens, are more susceptible and have increased bacterial burden compared with wildtype infected mice [39-42]. Later studies have also demonstrated the importance of NLRC4 during P. aeruginosa infection. Nlrc4-deficient macrophages are markedly resistant to $P$. aeruginosa-induced cell death and have reduced secretion of IL-1 $\beta$. P. aeruginosa isolates express the effector molecule exoenzyme $\mathrm{U}$ (ExoU), which is capable of inhibiting caspase-1-driven proinflammatory cytokine production [43]. Upon exposure to P. aeruginosa, Nlrc4-deficient mice have an increased bacterial burden in the bronchoalveolar lavage, but not in lung tissues when compared to control animals [44].

In contrast to these protective roles of NLRC4 during several Gram-negative bacterial infections, NLRC4 can also contribute to pathogenesis. Helicobacter pylori can cause chronic infection and lead to gastric ulcers and gastric adenocarcinomas. NLRC4 is crucial for IL-18 production from both human and murine gastric epithelial cells upon exposure to H. pylori. Nlrc4-deficient mice have reduced inflammation and control the bacterial burden more successfully than wildtype infected mice do [45], highlighting the pathogenic role NLRC4 can play during infection.

Overall, these studies show that the NAIP-NLRC4 inflammasome has dual roles during bacterial infection. NLRC4 protects the host against certain pathogens, such as Salmonella, Citrobacter or Legionella, but its activation may also be pathogenic by triggering strong inflammation during some infections, such as during Helicobacter infection.

\section{Role of NLRC4 in Autoinflammatory Diseases}

While NLRC4 activation is critical for activating the immune response and driving inflammation during bacterial infection, its overactivation can cause aberrant cell death and cytokine release. Therefore, mutations that cause hyperactivation of NLRC4 are potentially deleterious and can cause autoinflammatory disease. A de novo missense mutation (c.1009A > T, encoding p.Thr337Ser) affecting NLRC4 causes early-onset recurrent fever flares and macrophage activation syndrome (MAS). This mutation can trigger constitutive activation of caspase- 1 along with increased production of IL- $1 \beta$ and IL-18 in patient-derived and mutant NLRC4-transduced macrophages [46]. Another de novo gain-of-function mutation in NLRC4 causes a p.Val341Ala substitution in the helical domain 
1 (HD1), which causes constitutive inflammasome activation in syndromes like neonatalonset enterocolitis, periodic fever, and fatal or near-fatal episodes of autoinflammation [47]. Additionally, familial cold autoinflammatory syndrome (FCAS) in one Japanese family was found to be due to a missense mutation in NLRC4 causing enhanced activation of caspase- 1 along with increased production of IL-1 $\beta$. Expression of this mutant Nlrc4 in mice causes severe dermatitis, arthritis, and splenomegaly along with augmented infiltration of neutrophils and cold-induced exanthema [48]. A case study identified a novel mutation in the LRR domain of NLRC4 (c.G1965C, p.W655C) which contributes to autoinflammatory disease. The p.W655C NLRC4 mutation causes an increase in ASC speck formation and caspase-1-mediated IL- $1 \beta$ and IL-18 production, eventually causing increased cell death [49]. Another report identified a mutation in the LRR domain of NLRC4 that is associated with recurrent fever, skin erythema, and inflammatory arthritis symptoms [50].

Due to the pathogenic role of cytokine signaling in diseases associated with NLRC4 mutations, clinical blockade of these pathways has been pursued as a therapeutic strategy. Anakinra is an IL-1 receptor antagonist (IL-1Ra), and it is United States Food and Drug Administration (FDA) approved to treat certain inflammatory diseases [51]. Studies have shown that the combination of anakinra and rapamycin treatment could benefit patients with NLRC4 mutations [52]. Rapamycin has been used as an adjuvant to potentiate the action of anakinra. When given to an anakinra-treated patient, rapamycin resulted in reduced secretion of IL-18 along with a reduction in C-reactive protein and ferritin [52]. Recombinant IL-18 binding protein treatment also improves outcomes in patients with NLRC4 mutations who have MAS symptoms [53]. Future studies will continue to improve our ability to target molecules in the NLRC4 inflammasome activation cascade to provide new treatment strategies for patients.

\section{Role of NLRC4 in Cancer}

Aberrant activation of the inflammasome plays a major role in different stages of tumor progression including immunosuppression, proliferation, angiogenesis, and metastasis. Conversely, inflammasome activation can trigger tumor suppression by maintaining intestinal barrier integrity, suggesting that the inflammasome has dual roles in cancer development [54]. In 2010, studies showed the importance of NLR inflammasomes in colitis-associated cancer (CAC) by using animals deficient in inflammasome components, including Pycard, Casp1, Nlrp3, and Nlrc4 [55-57]. Mice lacking Pycard and Casp1 are highly susceptible to disease, morbidity, and polyp formation which are correlated with decreased levels of IL-1 $\beta$ and IL-18 at the tumor site [55]. Nlrp3-deficient mice also have CAC pathology; however, the disease outcome is less severe in $\mathrm{Nlrp3}^{-/-}$mice compared with $\mathrm{Asc}^{-/-}$or Casp $1^{-/}$animals, suggesting another inflammasome is also involved in reducing disease burden [55]. While this study identified no significant difference in CAC pathology or disease outcome between Nlrc4 $4^{-/}$and control animals [55], a parallel study found that treatment of $\mathrm{NlrC}^{-/-}$mice with the DNA damage-inducing compound azoxymethane (AOM) and dextran sulfate sodium (DSS) causes enlarged tumor volume, reduced apoptosis and enhanced colonic epithelial cell proliferation [58]. Additionally, $\mathrm{Nlrc}^{-/-}$mice are more susceptible to DSS-induced colitis compared with wildtype control mice [59]. Collectively, these findings indicate a crucial role for NLRC4 in protecting the gut.

On a cellular level, cytokines and chemokines are critical for tumor killing, and NLRC4 activation is essential for cytokine and chemokine production in tumor-associated macrophages. NLRC4 is necessary for the generation of IFN- $\gamma$-producing $\mathrm{CD} 4^{+}$and $\mathrm{CD} 8^{+}$ $\mathrm{T}$ cells in the murine model of B16F10 melanoma [60]. However, another recent study demonstrated that NLRC4 has no role in the progression of melanoma, with no difference observed in the tumor incidence between littermate wildtype and $\mathrm{Nlrc}^{-/-}$mice [28]. Alternatively, obesity-associated NLRC4 inflammasome activation along with IL-1 signaling trigger breast cancer progression [61]. The disease progression is driven primarily through vascular endothelial growth factor A (VEGFA) expression and angiogenesis. Furthermore, metformin treatment was found to inhibit obesity-associated tumor progression [61]. 
Overall, NLRC4 has been found to play contradictory roles in cancer progression; this may be due to lack of littermate controls in in vivo studies, differences in the gut microbiota between different animal facilities, differences in the genetic background of the mouse lines, and differences in the cancer models and experimental techniques. Future studies will be needed to clarify the function of NLRC4 in cancer using littermate controls.

\section{Role of NLRC4 in Pyroptosis, Apoptosis, Necroptosis, and PANoptosis}

Activation of different programmed cell death pathways, including pyroptosis, apoptosis, and necroptosis, is essential for clearing pathogens from the host upon infection. Pyroptosis and necroptosis are lytic, immunologically active forms of cell death, whereas apoptosis has historically been considered an immunologically silent cell death pathway; however more recent evidence suggests it is not always silent [62]. Recent work has identified that several infectious agents and sterile insults can induce inflammatory cell death through PANoptosis [63]. PANoptosis is a unique, physiologically relevant, inflammatory programmed cell death pathway activated by specific triggers and regulated by the PANoptosome, a molecular scaffold for contemporaneous engagement of key molecules from pyroptosis, apoptosis, and necroptosis [63-77]. Biochemical characterization has shown interactions between PANoptotic molecules [63]. Immunoprecipitation of NLRP3 confirmed that Z-DNA-binding protein 1 (ZBP1), receptor-interacting serine/threonineprotein kinase 3 (RIPK3) and receptor-interacting serine/threonine-protein kinase 1 (RIPK1) can interact with NLRP3. Similarly, immunoprecipitation of RIPK3 resulted in the coimmunoprecipitation of caspase-8, ASC, RIPK1, NLRP3, and ZBP1, suggesting that there are direct interactions between PANoptotic molecules to form a PANoptosome complex [63]. The synergy and crosstalk between these molecules, which were previously thought to be dedicated to their representative cell death pathways, is critical to modulate several inflammatory and infectious diseases and cancer.

While PANoptosis has most often been described in conjunction with NLRP3 inflammasome activation to date [63,68-77], multiple lines of evidence suggest that NLRC4 may also be playing a critical role in PANoptosis. Direct crosstalk between NLRC4 and apoptosis has been known for many years. Caspase-mediated cleavage of the DNA damage sensor poly (ADP-ribose) polymerase 1 (PARP1) is a hallmark of apoptosis. Activation of the NLRP3 and NLRC4 inflammasomes induces processing of full-length PARP1 into a fragment of $89 \mathrm{kDa}$. Macrophages deficient in Casp1, Nlrp3, Nlrc4, or Pycard cannot cleave PARP1, suggesting that protease-mediated inactivation of PARP1 is a shared feature of apoptotic and pyroptotic cell death pathways [65]; these finding laid the early foundation for the concept of PANoptosis.

Recently, a study showed that $S$. Typhimurium infection induces PANoptosis [63]. A subsequent study confirmed that there is an interconnection between pyroptosis, apoptosis, and necroptosis cell death pathways during $S$. Typhimurium infection [78]. Because $S$. Typhimurium induces PANoptosis and previous studies have clearly shown that the NAIP/NLRC4 inflammasome is activated during Salmonella infection, it is highly likely that the NAIP/NLRC4 inflammasome contributes to PANoptosis during bacterial infection. A recent study also identified activation of caspase- 1 and GSDMD (pyroptosis), caspase-8, caspase-7, and caspase-3 (apoptosis), and mixed lineage kinase domain-like pseudokinase (MLKL) (necroptosis) during Salmonella infection [63]. Combined deletion of the PANoptotic molecules Casp1, Casp11, Ripk3, and Casp8 protects macrophages from cell death during $S$. Typhimurium infection. However, deleting individual cell death components does not completely protect against cell death, suggesting a crucial role of PANoptosis during $S$. Typhimurium infection [63]. Further experimental evidence is needed to clarify the association of NAIP/NLRC4 with the molecules of the PANoptosome complex and to fully understand the role of NLRC4 in PANoptosis for host defense mechanisms (Figure 2). 


\section{Summary and Future Perspectives}

Research on the NAIP/NLRC4 inflammasome has progressed drastically in the last decade, especially with regard to the role of NLRC4 as an innate immune sensor, the importance of NAIPs in sensing to give NLRC4 its specificity, and the role of NLRC4 in autoinflammatory diseases and cancer.

Studies on NLRC4 identified that $S$. Typhimurium-infected BMDMs can trigger multiple cell death pathways $[63,78]$. Cell death is an important phenomenon to clear pathogens and allow host survival. Several studies have documented crosstalk between cell death pathways involving NLRC4 during infection and inflammatory conditions. In intestinal epithelial cell-specific Nlrc4-deficient mice, caspase-1 and GSDMD are not essential for cell death, whereas caspase- 1 and caspase- 8 are necessary for cell expulsion during Salmonella infection [30]. This study supports the findings that the NLRC4 inflammasome can recruit caspase-8, a key PANoptosome component, by interacting with the PYD of ASC and death effector domain of caspase-8 $[12,79,80]$. Additionally, NLRP1b and NLRC4 trigger caspase8-mediated apoptosis as an alternative cell death program in Casp1-deficient macrophages and intestinal epithelial organoids, providing further evidence for the crosstalk between these pathways. The caspase- 8 adaptor FADD is recruited to ASC specks, which serve as cytosolic platforms for caspase-8 activation and NLRP1b/NLRC4-induced apoptosis [81]. Similarly, during B. pseudomallei infection, the apoptotic caspase-7 is activated downstream of the NLRC 4 inflammasome and caspase- 1 and requires caspase- 9 processing. Therefore, the initiation of different cell death pathways seems to be an effective strategy to limit intracellular B. pseudomallei infection [82]. Furthermore, in an ischemic stroke model, the NLRC4 inflammasome mediates pyroptotic and apoptotic cell death in microglial cells [83]. In addition to pyroptosis and apoptosis, a study demonstrated that necroptosis can also contribute to the host immune response during $S$. Typhimurium infection [84]. Mechanistically, type I interferon-mediated necroptosis occurs in macrophages during $S$. Typhimurium infection, triggering an increased persistence of bacterial load. However, in the absence of the necroptotic molecule RIPK3, there is enhanced control of $S$. Typhimurium in vivo [84].

Overall, accumulating evidence suggests that crosstalk occurs between multiple cell death pathways involving NLRC4 in both infection and inflammatory diseases. Future research is needed to answer crucial questions such as how NLRC4 regulates PANoptosis, what are all the critical components involved in each cell death pathway and is there any specific master regulator which connects multiple cell death pathways during NLRC4 activation. Additionally, given that both protective and pathogenic roles of NLRC4 have been observed to date, it will be important to identify the specific infections and inflammatory conditions in which PANoptosis is beneficial vs detrimental. These answers will allow for the identification of new targets and therapeutic strategies to optimize NLRC4 activation for host defense while preventing autoinflammatory disease.

Author Contributions: All authors contributed to the writing and reviewing of this manuscript. All authors have read and agreed to the published version of the manuscript.

Funding: T.-D. Kanneganti is supported by funding from the National Institutes of Health (grants AI101935, AI124346, AR056296, and CA253095) and the American Lebanese Syrian Associated Charities. The content is solely the responsibility of the authors and does not necessarily represent the official views of the National Institutes of Health.

Acknowledgments: The authors acknowledge many investigators in the field whose primary data could not be cited in this review because of space limitations. We thank the members of the Kanneganti lab for helpful feedback during the editing of this review and Rebecca Tweedell, PhD, for scientific editing and writing support.

Conflicts of Interest: The authors declare that they have no conflict of interest. 


\section{References}

1. Martinon, F.; Burns, K.; Tschopp, J. The inflammasome: A molecular platform triggering activation of inflammatory caspases and processing of proIL-beta. Mol. Cell 2002, 10, 417-426. [CrossRef]

2. Kanneganti, T.D. Intracellular innate immune receptors: Life inside the cell. Immunol. Rev. 2020, 297, 5-12. [CrossRef] [PubMed]

3. Ding, J.; Wang, K.; Liu, W.; She, Y.; Sun, Q.; Shi, J.; Sun, H.; Wang, D.C.; Shao, F. Pore-forming activity and structural autoinhibition of the gasdermin family. Nature 2016, 535, 111-116. [CrossRef] [PubMed]

4. Liu, X.; Zhang, Z.; Ruan, J.; Pan, Y.; Magupalli, V.G.; Wu, H.; Lieberman, J. Inflammasome-activated gasdermin D causes pyroptosis by forming membrane pores. Nature 2016, 535, 153-158. [CrossRef]

5. Place, D.E.; Kanneganti, T.D. Cell death-mediated cytokine release and its therapeutic implications. J. Exp. Med. 2019, 216, 1474-1486. [CrossRef]

6. Man, S.M.; Kanneganti, T.D. Regulation of inflammasome activation. Immunol. Rev. 2015, 265, 6-21. [CrossRef]

7. Broz, P.; Dixit, V.M. Inflammasomes: Mechanism of assembly, regulation and signalling. Nat. Rev. Immunol. 2016, 16, 407-420. [CrossRef]

8. Kay, C.; Wang, R.; Kirkby, M.; Man, S.M. Molecular mechanisms activating the NAIP-NLRC4 inflammasome: Implications in infectious disease, autoinflammation, and cancer. Immunol. Rev. 2020, 297, 67-82. [CrossRef]

9. Poyet, J.L.; Srinivasula, S.M.; Tnani, M.; Razmara, M.; Fernandes-Alnemri, T.; Alnemri, E.S. Identification of Ipaf, a human caspase-1-activating protein related to Apaf-1. J. Biol. Chem. 2001, 276, 28309-28313. [CrossRef]

10. Li, Y.; Fu, T.M.; Lu, A.; Witt, K.; Ruan, J.; Shen, C.; Wu, H. Cryo-EM structures of ASC and NLRC4 CARD filaments reveal a unified mechanism of nucleation and activation of caspase-1. Proc. Natl. Acad. Sci. USA 2018, 115, 10845-10852. [CrossRef]

11. Man, S.M.; Hopkins, L.J.; Nugent, E.; Cox, S.; Gluck, I.M.; Tourlomousis, P.; Wright, J.A.; Cicuta, P.; Monie, T.P.; Bryant, C.E. Inflammasome activation causes dual recruitment of NLRC4 and NLRP3 to the same macromolecular complex. Proc. Natl. Acad. Sci. USA 2014, 111, 7403-7408. [CrossRef] [PubMed]

12. Man, S.M.; Tourlomousis, P.; Hopkins, L.; Monie, T.P.; Fitzgerald, K.A.; Bryant, C.E. Salmonella infection induces recruitment of Caspase-8 to the inflammasome to modulate IL-1beta production. J. Immunol. 2013, 191, 5239-5246. [CrossRef] [PubMed]

13. Broz, P.; Newton, K.; Lamkanfi, M.; Mariathasan, S.; Dixit, V.M.; Monack, D.M. Redundant roles for inflammasome receptors NLRP3 and NLRC4 in host defense against Salmonella. J. Exp. Med. 2010, 207, 1745-1755. [CrossRef] [PubMed]

14. Mariathasan, S.; Newton, K.; Monack, D.M.; Vucic, D.; French, D.M.; Lee, W.P.; Roose-Girma, M.; Erickson, S.; Dixit, V.M. Differential activation of the inflammasome by caspase-1 adaptors ASC and Ipaf. Nature 2004, 430, 213-218. [CrossRef] [PubMed]

15. Franchi, L.; Amer, A.; Body-Malapel, M.; Kanneganti, T.D.; Ozoren, N.; Jagirdar, R.; Inohara, N.; Vandenabeele, P.; Bertin, J.; Coyle, A.; et al. Cytosolic flagellin requires Ipaf for activation of caspase-1 and interleukin 1beta in salmonella-infected macrophages. Nat. Immunol. 2006, 7, 576-582. [CrossRef] [PubMed]

16. Miao, E.A.; Alpuche-Aranda, C.M.; Dors, M.; Clark, A.E.; Bader, M.W.; Miller, S.I.; Aderem, A. Cytoplasmic flagellin activates caspase-1 and secretion of interleukin 1beta via Ipaf. Nat. Immunol. 2006, 7, 569-575. [CrossRef]

17. Ren, T.; Zamboni, D.S.; Roy, C.R.; Dietrich, W.F.; Vance, R.E. Flagellin-deficient Legionella mutants evade caspase-1- and Naip5-mediated macrophage immunity. PLoS Pathog. 2006, 2, e18. [CrossRef]

18. Amer, A.; Franchi, L.; Kanneganti, T.D.; Body-Malapel, M.; Ozoren, N.; Brady, G.; Meshinchi, S.; Jagirdar, R.; Gewirtz, A.; Akira, S.; et al. Regulation of Legionella phagosome maturation and infection through flagellin and host Ipaf. J. Biol. Chem. 2006, 281, 35217-35223. [CrossRef]

19. Miao, E.A.; Mao, D.P.; Yudkovsky, N.; Bonneau, R.; Lorang, C.G.; Warren, S.E.; Leaf, I.A.; Aderem, A. Innate immune detection of the type III secretion apparatus through the NLRC4 inflammasome. Proc. Natl. Acad. Sci. USA 2010, 107, 3076-3080. [CrossRef]

20. Endrizzi, M.G.; Hadinoto, V.; Growney, J.D.; Miller, W.; Dietrich, W.F. Genomic sequence analysis of the mouse Naip gene array. Genome Res. 2000, 10, 1095-1102. [CrossRef]

21. Kofoed, E.M.; Vance, R.E. Innate immune recognition of bacterial ligands by NAIPs determines inflammasome specificity. Nature 2011, 477, 592-595. [CrossRef] [PubMed]

22. Zhao, Y.; Yang, J.; Shi, J.; Gong, Y.N.; Lu, Q.; Xu, H.; Liu, L.; Shao, F. The NLRC4 inflammasome receptors for bacterial flagellin and type III secretion apparatus. Nature 2011, 477, 596-600. [CrossRef] [PubMed]

23. Rayamajhi, M.; Zak, D.E.; Chavarria-Smith, J.; Vance, R.E.; Miao, E.A. Cutting edge: Mouse NAIP1 detects the type III secretion system needle protein. J. Immunol. 2013, 191, 3986-3989. [CrossRef] [PubMed]

24. Yang, J.; Zhao, Y.; Shi, J.; Shao, F. Human NAIP and mouse NAIP1 recognize bacterial type III secretion needle protein for inflammasome activation. Proc. Natl. Acad. Sci. USA 2013, 110, 14408-14413. [CrossRef] [PubMed]

25. Kortmann, J.; Brubaker, S.W.; Monack, D.M. Cutting Edge: Inflammasome Activation in Primary Human Macrophages Is Dependent on Flagellin. J. Immunol. 2015, 195, 815-819. [CrossRef]

26. Reyes Ruiz, V.M.; Ramirez, J.; Naseer, N.; Palacio, N.M.; Siddarthan, I.J.; Yan, B.M.; Boyer, M.A.; Pensinger, D.A.; Sauer, J.D.; Shin, S. Broad detection of bacterial type III secretion system and flagellin proteins by the human NAIP/NLRC4 inflammasome. Proc. Natl. Acad. Sci. USA 2017, 114, 13242-13247. [CrossRef]

27. Karki, R.; Lee, E.; Place, D.; Samir, P.; Mavuluri, J.; Sharma, B.R.; Balakrishnan, A.; Malireddi, R.K.S.; Geiger, R.; Zhu, Q.; et al. IRF8 Regulates Transcription of Naips for NLRC4 Inflammasome Activation. Cell 2018, 173, 920-933.e13. [CrossRef]

28. Tenthorey, J.L.; Chavez, R.A.; Thompson, T.W.; Deets, K.A.; Vance, R.E.; Rauch, I. NLRC4 inflammasome activation is NLRP3- and phosphorylation-independent during infection and does not protect from melanoma. J. Exp. Med. 2020, 217, e20191736. [CrossRef] 
29. Sellin, M.E.; Muller, A.A.; Felmy, B.; Dolowschiak, T.; Diard, M.; Tardivel, A.; Maslowski, K.M.; Hardt, W.D. Epithelium-intrinsic NAIP/NLRC4 inflammasome drives infected enterocyte expulsion to restrict Salmonella replication in the intestinal mucosa. Cell Host Microbe 2014, 16, 237-248. [CrossRef]

30. Rauch, I.; Deets, K.A.; Ji, D.X.; von Moltke, J.; Tenthorey, J.L.; Lee, A.Y.; Philip, N.H.; Ayres, J.S.; Brodsky, I.E.; Gronert, K.; et al. NAIP-NLRC4 Inflammasomes Coordinate Intestinal Epithelial Cell Expulsion with Eicosanoid and IL-18 Release via Activation of Caspase-1 and -8. Immunity 2017, 46, 649-659. [CrossRef]

31. Franchi, L.; Kamada, N.; Nakamura, Y.; Burberry, A.; Kuffa, P.; Suzuki, S.; Shaw, M.H.; Kim, Y.G.; Nunez, G. NLRC4-driven production of IL-1beta discriminates between pathogenic and commensal bacteria and promotes host intestinal defense. Nat. Immunol. 2012, 13, 449-456. [CrossRef] [PubMed]

32. Lara-Tejero, M.; Sutterwala, F.S.; Ogura, Y.; Grant, E.P.; Bertin, J.; Coyle, A.J.; Flavell, R.A.; Galan, J.E. Role of the caspase-1 inflammasome in Salmonella typhimurium pathogenesis. J. Exp. Med. 2006, 203, 1407-1412. [CrossRef] [PubMed]

33. Mamantopoulos, M.; Ronchi, F.; Van Hauwermeiren, F.; Vieira-Silva, S.; Yilmaz, B.; Martens, L.; Saeys, Y.; Drexler, S.K.; Yazdi, A.S.; Raes, J.; et al. Nlrp6- and ASC-Dependent Inflammasomes Do Not Shape the Commensal Gut Microbiota Composition. Immunity 2017, 47, 339-348.e4. [CrossRef] [PubMed]

34. Mamantopoulos, M.; Ronchi, F.; McCoy, K.D.; Wullaert, A. Inflammasomes make the case for littermate-controlled experimental design in studying host-microbiota interactions. Gut Microbes 2018, 9, 374-381. [CrossRef] [PubMed]

35. Ayres, J.S.; Trinidad, N.J.; Vance, R.E. Lethal inflammasome activation by a multidrug-resistant pathobiont upon antibiotic disruption of the microbiota. Nat. Med. 2012, 18, 799-806. [CrossRef] [PubMed]

36. Liu, Z.; Zaki, M.H.; Vogel, P.; Gurung, P.; Finlay, B.B.; Deng, W.; Lamkanfi, M.; Kanneganti, T.D. Role of inflammasomes in host defense against Citrobacter rodentium infection. J. Biol. Chem. 2012, 287, 16955-16964. [CrossRef]

37. Nordlander, S.; Pott, J.; Maloy, K.J. NLRC4 expression in intestinal epithelial cells mediates protection against an enteric pathogen. Mucosal Immunol. 2014, 7, 775-785. [CrossRef]

38. Goncalves, A.V.; Margolis, S.R.; Quirino, G.F.S.; Mascarenhas, D.P.A.; Rauch, I.; Nichols, R.D.; Ansaldo, E.; Fontana, M.F.; Vance, R.E.; Zamboni, D.S. Gasdermin-D and Caspase-7 are the key Caspase-1/8 substrates downstream of the NAIP5/NLRC4 inflammasome required for restriction of Legionella pneumophila. PLoS Pathog. 2019, 15, e1007886. [CrossRef]

39. Cerqueira, D.M.; Pereira, M.S.; Silva, A.L.; Cunha, L.D.; Zamboni, D.S. Caspase-1 but Not Caspase-11 Is Required for NLRC4Mediated Pyroptosis and Restriction of Infection by Flagellated Legionella Species in Mouse Macrophages and In Vivo. J. Immunol. 2015, 195, 2303-2311. [CrossRef]

40. Pereira, M.S.; Morgantetti, G.F.; Massis, L.M.; Horta, C.V.; Hori, J.I.; Zamboni, D.S. Activation of NLRC4 by flagellated bacteria triggers caspase-1-dependent and -independent responses to restrict Legionella pneumophila replication in macrophages and in vivo. J. Immunol. 2011, 187, 6447-6455. [CrossRef]

41. Pereira, M.S.; Marques, G.G.; Dellama, J.E.; Zamboni, D.S. The Nlrc4 Inflammasome Contributes to Restriction of Pulmonary Infection by Flagellated Legionella spp. that Trigger Pyroptosis. Front. Microbiol. 2011, 2, 33. [CrossRef] [PubMed]

42. Silveira, T.N.; Zamboni, D.S. Pore formation triggered by Legionella spp. is an Nlrc4 inflammasome-dependent host cell response that precedes pyroptosis. Infect. Immun. 2010, 78, 1403-1413. [PubMed]

43. Sutterwala, F.S.; Mijares, L.A.; Li, L.; Ogura, Y.; Kazmierczak, B.I.; Flavell, R.A. Immune recognition of Pseudomonas aeruginosa mediated by the IPAF/NLRC4 inflammasome. J. Exp. Med. 2007, 204, 3235-3245. [CrossRef]

44. Cohen, T.S.; Prince, A.S. Activation of inflammasome signaling mediates pathology of acute P. aeruginosa pneumonia. J. Clin. Investig. 2013, 123, 1630-1637. [CrossRef]

45. Semper, R.P.; Vieth, M.; Gerhard, M.; Mejias-Luque, R. Helicobacter pylori Exploits the NLRC4 Inflammasome to Dampen Host Defenses. J. Immunol. 2019, 203, 2183-2193. [CrossRef] [PubMed]

46. Canna, S.W.; de Jesus, A.A.; Gouni, S.; Brooks, S.R.; Marrero, B.; Liu, Y.; DiMattia, M.A.; Zaal, K.J.; Sanchez, G.A.; Kim, H.; et al. An activating NLRC4 inflammasome mutation causes autoinflammation with recurrent macrophage activation syndrome. Nat. Genet. 2014, 46, 1140-1146. [CrossRef] [PubMed]

47. Romberg, N.; Al Moussawi, K.; Nelson-Williams, C.; Stiegler, A.L.; Loring, E.; Choi, M.; Overton, J.; Meffre, E.; Khokha, M.K.; Huttner, A.J.; et al. Mutation of NLRC4 causes a syndrome of enterocolitis and autoinflammation. Nat. Genet. 2014, 46, 1135-1139. [CrossRef]

48. Kitamura, A.; Sasaki, Y.; Abe, T.; Kano, H.; Yasutomo, K. An inherited mutation in NLRC4 causes autoinflammation in human and mice. J. Exp. Med. 2014, 211, 2385-2396. [CrossRef]

49. Moghaddas, F.; Zeng, P.; Zhang, Y.; Schutzle, H.; Brenner, S.; Hofmann, S.R.; Berner, R.; Zhao, Y.; Lu, B.; Chen, X.; et al. Autoinflammatory mutation in NLRC4 reveals a leucine-rich repeat (LRR)-LRR oligomerization interface. J. Allergy Clin. Immunol. 2018, 142, 1956-1967.e6. [CrossRef]

50. Chear, C.T.; Nallusamy, R.; Canna, S.W.; Chan, K.C.; Baharin, M.F.; Hishamshah, M.; Ghani, H.; Ripen, A.M.; Mohamad, S.B. A novel de novo NLRC4 mutation reinforces the likely pathogenicity of specific LRR domain mutation. Clin. Immunol. 2020, 211, 108328. [CrossRef]

51. Tegtmeyer, K.; Atassi, G.; Zhao, J.; Maloney, N.J.; Lio, P.A. Off-Label studies on anakinra in dermatology: A review. J. Dermatolog. Treat. 2020, 1-14. [CrossRef] [PubMed] 
52. Barsalou, J.; Blincoe, A.; Fernandez, I.; Dal-Soglio, D.; Marchitto, L.; Selleri, S.; Haddad, E.; Benyoucef, A.; Touzot, F. Rapamycin as an Adjunctive Therapy for NLRC4 Associated Macrophage Activation Syndrome. Front. Immunol. 2018, 9, 2162. [CrossRef] [PubMed]

53. Canna, S.W.; Girard, C.; Malle, L.; de Jesus, A.; Romberg, N.; Kelsen, J.; Surrey, L.F.; Russo, P.; Sleight, A.; Schiffrin, E.; et al. Life-threatening NLRC4-associated hyperinflammation successfully treated with IL-18 inhibition. J. Allergy Clin. Immunol. 2017, 139, 1698-1701. [CrossRef] [PubMed]

54. Karki, R.; Kanneganti, T.D. Diverging inflammasome signals in tumorigenesis and potential targeting. Nat. Rev. Cancer 2019, 19, 197-214. [CrossRef]

55. Allen, I.C.; TeKippe, E.M.; Woodford, R.M.; Uronis, J.M.; Holl, E.K.; Rogers, A.B.; Herfarth, H.H.; Jobin, C.; Ting, J.P. The NLRP3 inflammasome functions as a negative regulator of tumorigenesis during colitis-associated cancer. J. Exp. Med. 2010, 207, 1045-1056. [CrossRef]

56. Zaki, M.H.; Boyd, K.L.; Vogel, P.; Kastan, M.B.; Lamkanfi, M.; Kanneganti, T.D. The NLRP3 inflammasome protects against loss of epithelial integrity and mortality during experimental colitis. Immunity 2010, 32, 379-391. [CrossRef]

57. Zaki, M.H.; Vogel, P.; Body-Malapel, M.; Lamkanfi, M.; Kanneganti, T.D. IL-18 production downstream of the Nlrp3 inflammasome confers protection against colorectal tumor formation. J. Immunol. 2010, 185, 4912-4920. [CrossRef]

58. Hu, B.; Elinav, E.; Huber, S.; Booth, C.J.; Strowig, T.; Jin, C.; Eisenbarth, S.C.; Flavell, R.A. Inflammation-induced tumorigenesis in the colon is regulated by caspase-1 and NLRC4. Proc. Natl. Acad. Sci. USA 2010, 107, 21635-21640. [CrossRef]

59. Carvalho, F.A.; Nalbantoglu, I.; Aitken, J.D.; Uchiyama, R.; Su, Y.; Doho, G.H.; Vijay-Kumar, M.; Gewirtz, A.T. Cytosolic flagellin receptor NLRC4 protects mice against mucosal and systemic challenges. Mucosal Immunol. 2012, 5, 288-298. [CrossRef]

60. Janowski, A.M.; Colegio, O.R.; Hornick, E.E.; McNiff, J.M.; Martin, M.D.; Badovinac, V.P.; Norian, L.A.; Zhang, W.; Cassel, S.L.; Sutterwala, F.S. NLRC4 suppresses melanoma tumor progression independently of inflammasome activation. J. Clin. Investig. 2016, 126, 3917-3928. [CrossRef]

61. Kolb, R.; Phan, L.; Borcherding, N.; Liu, Y.; Yuan, F.; Janowski, A.M.; Xie, Q.; Markan, K.R.; Li, W.; Potthoff, M.J.; et al. Obesityassociated NLRC4 inflammasome activation drives breast cancer progression. Nat. Commun. 2016, 7, 13007. [CrossRef] [PubMed]

62. Wang, Y.; Gao, W.; Shi, X.; Ding, J.; Liu, W.; He, H.; Wang, K.; Shao, F. Chemotherapy drugs induce pyroptosis through caspase-3 cleavage of a gasdermin. Nature 2017, 547, 99-103. [CrossRef] [PubMed]

63. Christgen, S.; Zheng, M.; Kesavardhana, S.; Karki, R.; Malireddi, R.K.S.; Banoth, B.; Place, D.E.; Briard, B.; Sharma, B.R.; Tuladhar, S.; et al. Identification of the PANoptosome: A Molecular Platform Triggering Pyroptosis, Apoptosis, and Necroptosis (PANoptosis). Front. Cell. Infect. Microbiol. 2020, 10, 237. [CrossRef]

64. Lamkanfi, M.; Kanneganti, T.D.; Van Damme, P.; Vanden Berghe, T.; Vanoverberghe, I.; Vandekerckhove, J.; Vandenabeele, P.; Gevaert, K.; Nunez, G. Targeted peptidecentric proteomics reveals caspase-7 as a substrate of the caspase-1 inflammasomes. Mol. Cell. Proteom. 2008, 7, 2350-2363. [CrossRef]

65. Malireddi, R.K.; Ippagunta, S.; Lamkanfi, M.; Kanneganti, T.D. Cutting edge: Proteolytic inactivation of poly(ADP-ribose) polymerase 1 by the Nlrp3 and Nlrc4 inflammasomes. J. Immunol. 2010, 185, 3127-3130. [CrossRef] [PubMed]

66. Gurung, P.; Anand, P.K.; Malireddi, R.K.; Vande Walle, L.; Van Opdenbosch, N.; Dillon, C.P.; Weinlich, R.; Green, D.R.; Lamkanfi, M.; Kanneganti, T.D. FADD and caspase-8 mediate priming and activation of the canonical and noncanonical Nlrp3 inflammasomes. J. Immunol. 2014, 192, 1835-1846. [CrossRef] [PubMed]

67. Karki, R.; Sharma, B.R.; Tuladhar, S.; Williams, E.P.; Zalduondo, L.; Samir, P.; Zheng, M.; Sundaram, B.; Banoth, B.; Malireddi, R.K.S.; et al. Synergism of TNF- $\alpha$ and IFN- $\gamma$ triggers inflammatory cell death, tissue damage, and mortality in SARS-CoV-2 infection and cytokine shock syndromes. Cell 2020, 184, 149-168.e17. [CrossRef]

68. Malireddi, R.K.S.; Gurung, P.; Mavuluri, J.; Dasari, T.K.; Klco, J.M.; Chi, H.; Kanneganti, T.D. TAK1 restricts spontaneous NLRP3 activation and cell death to control myeloid proliferation. J. Exp. Med. 2018, 215, 1023-1034. [CrossRef]

69. Zheng, M.; Williams, E.P.; Malireddi, R.K.S.; Karki, R.; Banoth, B.; Burton, A.; Webby, R.; Channappanavar, R.; Jonsson, C.B.; Kanneganti, T.-D. Impaired NLRP3 inflammasome activation/pyroptosis leads to robust inflammatory cell death via caspase-8/RIPK3 during coronavirus infection. J. Biol. Chem. 2020, 295, 14040-14052. [CrossRef]

70. Kuriakose, T.; Man, S.M.; Subbarao Malireddi, R.K.; Karki, R.; Kesavardhana, S.; Place, D.E.; Neale, G.; Vogel, P.; Kanneganti, T.-D. ZBP1/DAI is an innate sensor of influenza virus triggering the NLRP3 inflammasome and programmed cell death pathways. Sci. Immunol. 2016, 1, aag2045. [CrossRef]

71. Kesavardhana, S.; Malireddi, R.K.S.; Burton, A.R.; Porter, S.N.; Vogel, P.; Pruett-Miller, S.M.; Kanneganti, T.-D. The Z $\alpha 2$ domain of ZBP1 is a molecular switch regulating influenza-induced PANoptosis and perinatal lethality during development. J. Biol. Chem. 2020, 295, 8325-8330. [CrossRef] [PubMed]

72. Malireddi, R.K.S.; Gurung, P.; Kesavardhana, S.; Samir, P.; Burton, A.; Mummareddy, H.; Vogel, P.; Pelletier, S.; Burgula, S.; Kanneganti, T.-D. Innate immune priming in the absence of TAK1 drives RIPK1 kinase activity-independent pyroptosis, apoptosis, necroptosis, and inflammatory disease. J. Exp. Med. 2020, 217. [CrossRef] [PubMed]

73. Zheng, M.; Karki, R.; Vogel, P.; Kanneganti, T.-D. Caspase-6 Is a Key Regulator of Innate Immunity, Inflammasome Activation, and Host Defense. Cell 2020, 181, 674-687.e13. [CrossRef] [PubMed]

74. Banoth, B.; Tuladhar, S.; Karki, R.; Sharma, B.R.; Briard, B.; Kesavardhana, S.; Burton, A.; Kanneganti, T.-D. ZBP1 promotes fungi-induced inflammasome activation and pyroptosis, apoptosis, and necroptosis (PANoptosis). J. Biol. Chem. 2020, 295, 18276-18283. [CrossRef] 
75. Lukens, J.R.; Gurung, P.; Vogel, P.; Johnson, G.R.; Carter, R.A.; McGoldrick, D.J.; Bandi, S.R.; Calabrese, C.R.; Walle, L.V.; Lamkanfi, M.; et al. Dietary modulation of the microbiome affects autoinflammatory disease. Nature 2014, 516, 246-249. [CrossRef]

76. Gurung, P.; Burton, A.; Kanneganti, T.-D. NLRP3 inflammasome plays a redundant role with caspase 8 to promote IL-1 $\beta-$ mediated osteomyelitis. Proc. Natl. Acad. Sci. USA 2016, 113, 4452-4457. [CrossRef]

77. Karki, R.; Sharma, B.R.; Lee, E.; Banoth, B.; Malireddi, R.K.S.; Samir, P.; Tuladhar, S.; Mummareddy, H.; Burton, A.R.; Vogel, P.; et al. Interferon regulatory factor 1 regulates PANoptosis to prevent colorectal cancer. JCI Insight 2020, 5, e136720. [CrossRef]

78. Doerflinger, M.; Deng, Y.; Whitney, P.; Salvamoser, R.; Engel, S.; Kueh, A.J.; Tai, L.; Bachem, A.; Gressier, E.; Geoghegan, N.D.; et al. Flexible Usage and Interconnectivity of Diverse Cell Death Pathways Protect against Intracellular Infection. Immunity 2020, 53, 533-547.e7. [CrossRef]

79. Masumoto, J.; Dowds, T.A.; Schaner, P.; Chen, F.F.; Ogura, Y.; Li, M.; Zhu, L.; Katsuyama, T.; Sagara, J.; Taniguchi, S.; et al. ASC is an activating adaptor for NF-kappa B and caspase-8-dependent apoptosis. Biochem. Biophys. Res. Commun. 2003, 303, 69-73. [CrossRef]

80. Vajjhala, P.R.; Lu, A.; Brown, D.L.; Pang, S.W.; Sagulenko, V.; Sester, D.P.; Cridland, S.O.; Hill, J.M.; Schroder, K.; Stow, J.L.; et al. The Inflammasome Adaptor ASC Induces Procaspase-8 Death Effector Domain Filaments. J. Biol. Chem. 2015, 290, 29217-29230. [CrossRef]

81. Van Opdenbosch, N.; Van Gorp, H.; Verdonckt, M.; Saavedra, P.H.V.; de Vasconcelos, N.M.; Goncalves, A.; Vande Walle, L.; Demon, D.; Matusiak, M.; Van Hauwermeiren, F.; et al. Caspase-1 Engagement and TLR-Induced c-FLIP Expression Suppress ASC/Caspase-8-Dependent Apoptosis by Inflammasome Sensors NLRP1b and NLRC4. Cell Rep. 2017, 21, 3427-3444. [CrossRef] [PubMed]

82. Bast, A.; Krause, K.; Schmidt, I.H.; Pudla, M.; Brakopp, S.; Hopf, V.; Breitbach, K.; Steinmetz, I. Caspase-1-dependent and -independent cell death pathways in Burkholderia pseudomallei infection of macrophages. PLoS Pathog. 2014, 10, e1003986. [CrossRef] [PubMed]

83. Poh, L.; Kang, S.W.; Baik, S.H.; Ng, G.Y.Q.; She, D.T.; Balaganapathy, P.; Dheen, S.T.; Magnus, T.; Gelderblom, M.; Sobey, C.G.; et al. Evidence that NLRC4 inflammasome mediates apoptotic and pyroptotic microglial death following ischemic stroke. Brain Behav. Immun. 2019, 75, 34-47. [CrossRef] [PubMed]

84. Robinson, N.; McComb, S.; Mulligan, R.; Dudani, R.; Krishnan, L.; Sad, S. Type I interferon induces necroptosis in macrophages during infection with Salmonella enterica serovar Typhimurium. Nat. Immunol. 2012, 13, 954-962. [CrossRef] 